\title{
Dissecting the Microscopic Anatomy of Colon Crypts in Non-dysplastic Sessile Serrated Polyps
}

\author{
CARLOS A. RUBIO ${ }^{1}$ and PETER T. SCHMIDT ${ }^{2}$ \\ ${ }^{1}$ Gastrointestinal and Liver Research Laboratory, Department of Pathology, \\ Karolinska Institute and University Hospital, Stockholm, Sweden; \\ ${ }^{2}$ Department of Medicine Solna, Center for Digestive Diseases, \\ Karolinska Institute and University Hospital, Stockholm, Sweden
}

\begin{abstract}
Background/Aim: Sessile serrated polyps (SSP) are characterized by crypts with corrupted shapes (CCS). Materials and Methods: The number of CCS and the lateral size of 60 non-dysplastic SSP (NDSSP) were investigated. Results: Out of $60 \mathrm{NDSSP}, 34$ were small $(\leq 9 \mathrm{~mm})$ and 26 , large $(\geq 10 \mathrm{~mm})$. In total, 1,101 CCS were recorded: 547 CCS were connected to the lumen (CCSL) and 554 CCS were not (CCSNL). The lateral size of NDSSP, the total number of CCS and the number of CCSNL were significantly higher in large NDSSP than in small NDSSP. Conversely, the number of CCS connected to the lumen $/ \mathrm{mm}$ (CCSL/mm) and of crypts with normal shapes connected to the lumen/mm $(C C S N L / \mathrm{mm})$, were significantly lower in large NDSSP than in small NDSSP. Conclusion: The lateral expansion of large NDSSP ensues via increased numbers of CCS at the expense of a decreased number of both CCSL/mm and CCSNL/mm.
\end{abstract}

Progression from adenoma to carcinoma is one of the most intensively investigated trails in human malignancies (1-3). In later years, colorectal serrated polyps, comprising hyperplastic polyps (HP), sessile serrated adenomas (SSA/P), and traditional serrated adenomas (TSA), have received much attention (4-6).

Although the most common of all serrated polyps -namely HP- is considered innocuous, patients with hyperplastic polyposis coli syndrome or serrated polyposis syndrome are at high risk to develop colorectal cancer (7-10). Sporadic, solitary SSA/P and TSA are also prone to progress to

Correspondence to: Carlos A. Rubio, MD, Ph.D., Gastrointestinal and Liver Pathology Research Laboratory, Department of Pathology, Karolinska Institute and University Hospital, 17176, Stockholm, Sweden. Tel: +46 851774527, Fax: +46 851774524, e-mail: Carlos.Rubio@ki.se

Key Words: Colon, crypt deformity, sessile serrated polyps. invasive carcinoma (11-13). It has been estimated that about $30 \%$ of all colorectal carcinomas in human, progress via the serrated pathway (11).

At endoscopical examination, SSA/P appear as a flat or minimally elevated, pale lesion, with indistinct borders and loss of the vascular pattern (14). However, SSA/P are often concealed by a mucus cap or debris $(14,15)$. Overlooked SSA/P seem to account for a significant proportion of intervalcancers evolving between two surveillance colonoscopic examinations (15).

At histological examination, SSA/P are characterized by epithelial serrations often reaching the lower third of the crypts, and by crypts with corrupted shapes (CCS) portraying bootshaped, L-shaped or inverted-T basal dilatations. These corfupted shapes often display lateral extensions, running parallel to the muscularis mucosae (crypt horizontalization) (16-19). Occasionally, pseudo-invasion into the lamina propria may occur in SSA/P (16-19). According to some authors, the presence of a single boot-like crypt, a single L-like crypt or a single inverted T-shaped crypt, is indicative of SSA/P (19).

The aim of this investigation was to assess the frequency of CCS in a cohort of NDSSP without dysplasia; these lesions will be referred to as non-dysplastic sessile serrated polyps or with the acronym NDSSP.

\section{Materials and Methods}

Sections (4 $\mu \mathrm{m}$ thick) from 60 endoscopically-removed SSA/P, stained with hematoxylin and eosin $(\mathrm{H} \& \mathrm{E})$, were retrieved from the files of the Gastrointestinal Research Laboratory of this Department.

Recording the lateral size of NDSSP at histology. The lateral size of NDSSP in $\mathrm{mm}$, was assessed in a standard Nikon light microscope $(10 \times$ ocular and a $4 \times$ Plan Apo objective (lens aperture $0.20)$ using a calibrated ocular microscale.

Crypts with CCS. Colonic crypts with boot-shapes, L-shapes, inverted T-shapes, asymmetric fission, with irregular scalloped outlines (Figure 1), or with mitochondrium-like cristae due to transversal bridges of serrated epithelium (Figure 1e). 
Entire (complete) crypts with corrupted shapes reaching the lumen (ECCSL). Vertically-cut CCS connected to the lumen of the colon, i.e. exposing their entire length, from the bottom of the crypts up to their luminal orifice.

CCS not connected with the lumen. CCS with tangentially-cut bottoms. Entire crypts with normal shapes (ECNS). Serrated crypts with normal shapes exposing their entire length, from the bottom of the crypts up to their luminal orifice.

Sections also contained many tangentially-cut crypt bottoms lined with normal epithelium that were difficult to evaluate; they were not included in the study.

Statistical analysis. The non-parametric Kruskal-Wallis test was applied to compare difference between groups. Statistic significance was defined as $p<0.05$.

This study was approved by The Regional Ethical Review Board in Stockholm (no. 2018/688-32 and 2018/2024-32).

\section{Results}

Size in NDSSP. The results in Table I show that the mean lateral length in the 60 NDSSP was $9.6 \mathrm{~mm}$ : the mean lateral size in the 34 small ( $\leq 9 \mathrm{~mm}$ ) NDSSP was $6.2 \mathrm{~mm}$, and in the 26 large $(\geq 10 \mathrm{~mm})$ NDSSP, it was $14.1 \mathrm{~mm}(p<0.05)$.

Total number of CCS. A total of 1101 CCS were recorded in the 60 NDSSP (mean=18.4 CCS): $470 \mathrm{CCS}$ were found in the 34 small NDSSP (mean=13.8 CCS) and $631 \mathrm{CCS}$ in the 26 large NDSSP (mean=24.3 CCS) $(p<0.05)$.

Number of CCS not connected to the lumen. A total of 554 CCS without luminal connexion were found in the 60 NDSSP (mean=9.2): $178 \mathrm{CCS}$ (mean 5.2 CCS) were recorded in the 34 small NDSSP and $376 \mathrm{CCS}$ (mean=24.3 CCS $)$ in the 26 large NDSSP $(p<0.05)$.

Number of entire CCS connected to the lumen (ECCSL). Table I shows that the number of ECCSL in the 60 NDSSP was 547 ECCSL (mean=9.1 ECCSL). Similar frequencies of ECCSL were found in small NDSSP and in large NDSSP (mean=8.6 ECCSL, and mean=9.8 ECCSL, respectively).

Number of entire crypts with normal shapes connected to the lumen (ECNSL). A total of 394 ECNSL (mean=6.6 ECNSL) were found intercalated amidst the CCS in the 60 NDSSP. Similar frequencies of ECNSL were found in small NDSSP and in large NDSSP (mean=6.4 ECNSL and mean 6.8 ECNSL, respectively).

Number of entire CCS connected to the lumen per $\mathrm{mm}$ $(E C C S L / \mathrm{mm})$. The results in Table I show that a mean of $9.95 \mathrm{ECCSL} / \mathrm{mm}$ were found in the $60 \mathrm{NDSSP}: 1.38$ $\mathrm{ECCSL} / \mathrm{mm}$ in small NDSSP but only $0.69 \mathrm{ECCSL} / \mathrm{mm}$ in large NDSSP $(p<0.05)$.
Number of entire crypts with normal shapes connected to the lumen per $\mathrm{mm}(\mathrm{ECNSL} / \mathrm{mm})$. A mean of $0.68 \mathrm{ECNSL} / \mathrm{mm}$ were found in the $60 \mathrm{NDSSP}: 1.02 \mathrm{ECNSL} / \mathrm{mm}$ in small NDSSP but only $0.48 \mathrm{ECNSL} / \mathrm{mm}$, in large NDSSP $(p<0.05)$.

\section{Discussion}

In similarity with the descriptions of SSA/P in the literature (4-6), we found in NDSSP, crypts with corrupted shapes portrying cystic dilatations, boot-like shapes, L-like shapes, inverted T-like shapes (i.e. with axial-polarity distortions, or with mitochondrium-like cristae Figure 1e).

As anticipated, the lateral size (in $\mathrm{mm}$ ) as well as the number of crypts with CCS were increased in large NDSSP than in small NDSSP. The pertinent questions are: i) Are the proportions of CCS and of interspersed CNS, constant in small and in large NDSSP? If this is the case, then during their lateral expansion, large NDSSP would retain the same proportions of cryptal architectural deformities as in small NDSSP. Conversely, ii) Is the increased number of CCS attained in large NDSSP higher than in small NDSSP because the number of interspersed ECNSL is decreased in large NDSSP? If that is the case, then profound cryptal changes have occured during the evolution from small NDSSP to large NDSSP. Since these questions are crucial for our understanding of the evolution of large NDSSP, we forensically examined six different crypt parameters in small and in large NDSSP. We found that the total number of CCS and the number of CCS not connected to the lumen were significantly increased in large $(\geq 10 \mathrm{~mm}) \mathrm{SSA} / \mathrm{P}$, the number of entire CCS per $\mathrm{mm}$ (ECCSL/mm), and the number of entire crypts with normal shapes per $\mathrm{mm}$ (ECNSL/mm) found within the confines of NDSSP were significantly lower in large NDSSP. Hence, it would appear that the number of CCS unconnected to the lumen had replaced ECCSL/mm and ECNSL in large NDSSP.

The configurations of CCS in NDSSP, in contrast to the configurations of the crypts in the normal colon, inasmuch as in the latter, they are aligned uniformly, as tightly-packed invaginations of approximately the same size, perpendicular to the surface epithelium, with their blind-ends "resting" on the muscularis mucosae (20-22). Despite the fact that crypts replicate by symmetric fission, beginning at their base and proceeding upwards until two identical individual crypts are formed, crypt branching is seldom found in fixed preparations from the normal colon (23). In this context, a recent review of the normal mucosa showed that only three out of 22 colon segments proximal or distal to surgically removed colon cancer had occasional CCS (mean=3.7 CCS, range $=2-5 \mathrm{CCS}$ ) (24). The remnant colonic crypts in the colonic segments of these three patients as well as in the colonic segments from the remaining 19 patients had crypts 

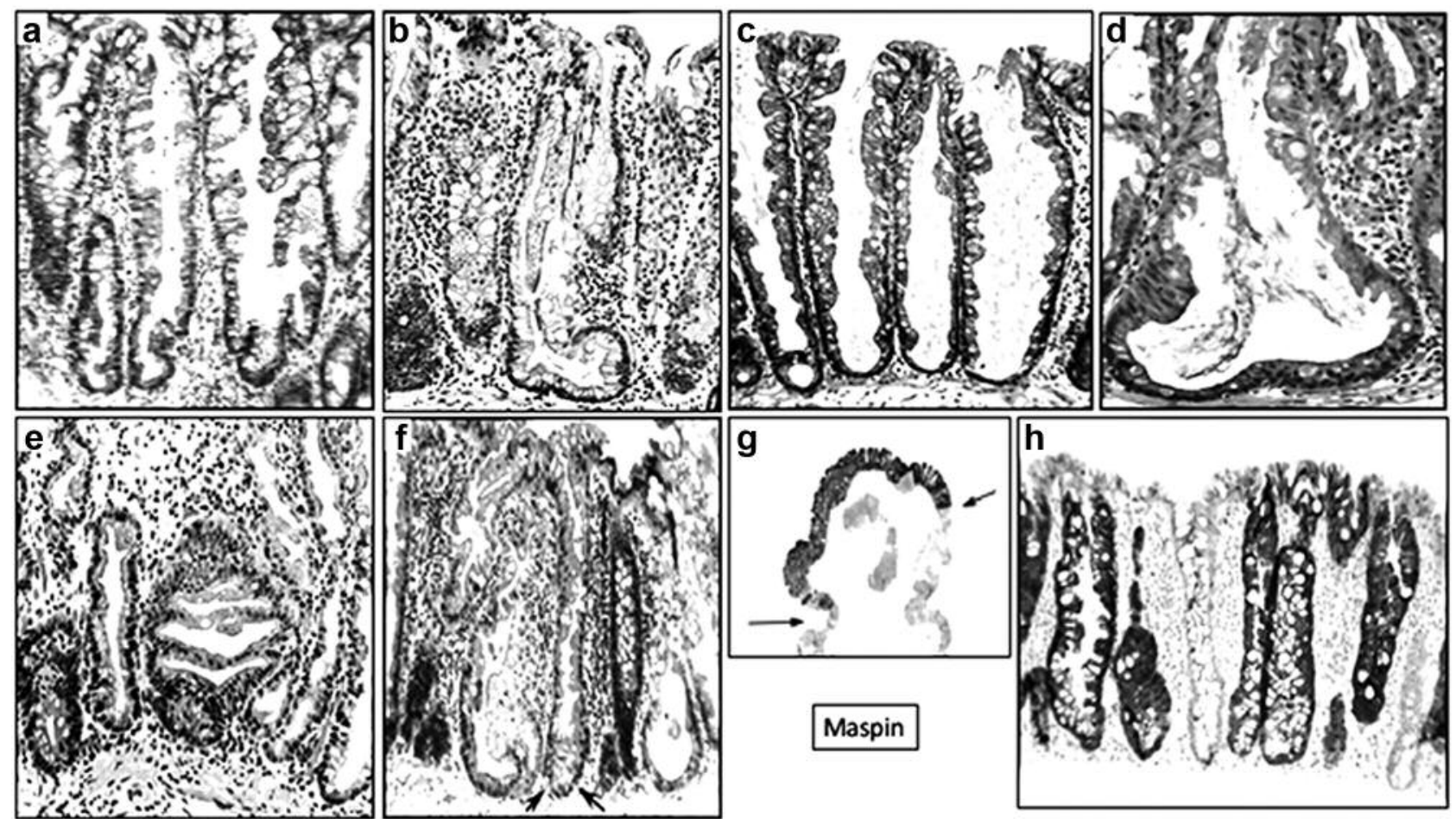

Figure 1. Different views of non-dysplastic sessile serrated polyps of the colon portraying crypts with serrated indentations having corrupted shapes (CCS), such as a: Crypt-trifurcation, $b$ : Basal lateral, L-shaped extension. $c$ : Bottle-shaped luminal dilatations, $d$ : Basal bi-lateral extensions, $e$ : Mitochondria-like transversal cristae due to bridges of serrated epithelium, $f$ : Crypt with normal shape (arrows) alternating with crypts with corrupte shapes, g: Non-dysplastic sessile serrated polyp immuno-stained with maspin; note sharp contrast (arrows) between the maspin-positive nondysplastic sessile serrated polyp and the unstained normal colon mucosa $h$ : Closer view of a non-dysplastic sessile serrated polyp following maspin immunostaining disclosing an unstained interspersed crypt with normal shape, sided by maspin-immunoreactive CCS $(a, b, c, e, f: H \& E \times 10, d$ : $H \& E \times 20)$, g: Maspin immunostain, $\times 1, h$ : Maspin immunostain, $\times 10)$.

Table I. The lateral size (in $\mathrm{mm}$ ) and various crypt parameters in 60 colonic non-dysplastic sessile serrated polyps (NDSSP); 34 small NDSSP ( $\leq$ $9 \mathrm{~mm})$ and 26 large NDSSP $(\geq 10 \mathrm{~mm})$.

\begin{tabular}{|c|c|c|c|}
\hline & $\begin{array}{c}60 \\
\text { NDSSP }\end{array}$ & $\begin{array}{c}34 \text { small } \\
\operatorname{NDSSP}(\leq 9 \mathrm{~mm})\end{array}$ & $\begin{array}{c}26 \text { large } \\
\operatorname{NDSSP}(\geq 10 \mathrm{~mm})\end{array}$ \\
\hline Size of NDSSP in histological sections (lateral length in $\mathrm{mm}$ ) & $\begin{array}{c}578 \mathrm{~mm} \\
\text { mean } 9.6 \mathrm{~mm}(3-28 \mathrm{~mm})\end{array}$ & $\begin{array}{c}211 \mathrm{~mm} \\
\text { mean } 6.2 \mathrm{~mm}(3-9 \mathrm{~mm})\end{array}$ & $\begin{array}{c}367 \mathrm{~mm} \\
\text { mean } 14.1(10-28 \mathrm{~mm})\end{array}$ \\
\hline Total number of CCS & $\begin{array}{c}1101 \\
\text { mean } 18.4(6-70)\end{array}$ & $\begin{array}{c}470 \\
\text { mean } 13.8(6-34)\end{array}$ & $\begin{array}{c}631 \\
\text { mean } 24.3(7-70)\end{array}$ \\
\hline Number of CCS not connected to the lumen & $\begin{array}{c}554 \\
\text { mean } 9.2(4-30)\end{array}$ & $\begin{array}{c}178 \\
\text { mean } 5.2(4-22)\end{array}$ & $\begin{array}{c}376 \\
\text { mean } 14.5(5-30)\end{array}$ \\
\hline ECCSL (number of entire CCS connected to the lumen) & $\begin{array}{l}547 \\
\text { mean } 9.1(2-27)\end{array}$ & $\begin{array}{c}292 \\
\text { mean } 8.6(2-27)\end{array}$ & $\begin{array}{l}255 \\
\text { mean } 9.8(2-22)\end{array}$ \\
\hline $\begin{array}{l}\text { ECNSL (number of entire crypts with normal } \\
\text { shapes connected to the lumen) }\end{array}$ & $\begin{array}{l}394 \\
\text { mean } 6.6(0-22)\end{array}$ & $\begin{array}{c}216 \\
\text { mean } 6.4(0-17)\end{array}$ & $\begin{array}{c}178 \\
\text { mean } 6.8(1-22)\end{array}$ \\
\hline Number of ECCSL/mm & $0.95 \mathrm{ECCS} / \mathrm{mm}$ & $1.38 \mathrm{ECCS} / \mathrm{mm}$ & $0.69 \mathrm{CCCS} / \mathrm{mm}$ \\
\hline Number of ECNSL/mm & $0.68 \mathrm{ECNSL} / \mathrm{mm}$ & $1.02 \mathrm{ECNSL} / \mathrm{mm}$ & $0.48 \mathrm{ECNSL} / \mathrm{mm}$ \\
\hline
\end{tabular}

CCS: Serrated crypts with corrupted shapes; CNS: serrated crypts with normal shapes; CCSL: crypts with corrupted shapes connected to the lumen; ECCSCL: Entire crypts with corrupted shapes connected to the lumen: Vertically-cut crypts with corrupted shapes exposing their entire length, from the bottom of the crypts up to their luminal orifice; ECNSL: Entire crypts with normal shapes connected to the lumen: Vertically-cut crypts with normal shapes exposing their entire length, from the bottom of the crypts up to their luminal orifice. 
with normal shapes (24). As a corollary, the vast majority of the normal mucosa of patients having synchronously a colon cancer, display crypts with normal shapes.

It has been postulated that a single boot-like crypt, a single L-like crypt or a single inverted T-shaped crypt, is indicative of SSA/P (19). If that is the case, what is the role played by the entire crypts with normal shapes reaching the lumen (ECNSL) interspersed within the boundaries of NDSSP? In this context, previous studies showed that SSA/P expressed the tumor-suppressor protein maspin, whereas the normal crypts of normal mucosa surrounding the SSA/P were maspin-negative (Figure 1g) (25). Maspin is a $42-\mathrm{kDa}$ serine proteinase inhibitor encoded by the SERPINB5 gene, a tumor-suppressor protein that stimulates apoptosis and inhibits motility, invasion and cancer metastasis (26). Payne et al. found maspin expression in the luminal aspect of the colonic crypts of HP/adenomatous polyps, in high-grade tumors and in the colonic tissue from a patient with ulcerative colitis harbouring an adenocarcinoma, while the crypts in the normal colon were maspin negative (27). The finding that ECNSL were interspersed within the boundaries of NDSSP, prompted us to review filed sections immunostained with maspin (25). The re-examination revealed that while CCS expressed maspin, the normal crypt surrounding the lesion as well as some intercalated serrated crypts with normal shapes were maspin negative (Figur $1 \mathrm{~h}$ ). Based on these findings we are prone to speculate that some of the ECNSL interspersed amongst CCS found within the confines of NDSSP might be crypts not yet involved in the molecular process of tumor-suppression (as they remained unstained by the protein maspin).

Considering that human colonic crypts typically divide at most once or twice during a lifetime, with an average crypt cycle length of 36 years (28), the accretion of CCS within the limits of NDSSP is a remarkable finding.

In summary, the present findings suggest that the lateral expansion of large NDSSP ensues with increased numbers of CCS at the expense of a decreased number of ECCSL $/ \mathrm{mm}$ and of ECNSL $/ \mathrm{mm}$. These unexpected quantitavive histological findings open new vistas on the corrupted cryptogenesis that unfold during the evolution from small to large NDSSP in the human colon.

\section{Conflicts of Interest}

The Authors have no conflicts of interest to disclose regarding this study.

\section{Authors' Contributions}

CAR: designed the experiment, performed procedures, data analysis and wrote the manuscript; PTS harvested SSP at endoscopy, introduced suggestions and approved the final manuscript.

\section{References}

1 Muto T, Bussey HJ and Morson BC: The evolution of cancer of the colon and rectum. Cancer 36: 2251-2270, 1975. PMID: 1203876.

2 Leslie A, Carey FA, Pratt NR, and Steele RJ: The colorectal adenoma-carcinoma sequence. Br J Surg 89: 845-860, 2002. PMID: 12081733. DOI: 10.1046/j.1365-2168.2002.02120.x

3 Brenner H, Kloor M and Pox CP: Colorectal cancer. Lancet 383: 1490-1502, 2014. PMID: 24766949. DOI: 10.1016/S01406736(14)60699-1

4 Snover DC: Update on the serrated pathway to colorectal carcinoma. Hum Pathol 42: 1-10, 2011. PMID: 20869746. DOI: 10.1016/j.humpath.2010.06.002

5 Choi EY and Appelman HD: A historical perspective and exposé on serrated polyps of the colorectum. Arch Pathol Lab Med 140: 1079-1084, 2016. PMID: 27684980. DOI: 10.5858/arpa.20160278-RA

6 Bettington M, Brown I, Rosty C, Walker N, Liu C, Croese J, Rahman T, Pearson SA, McKeone D, Leggett B, and Whitehall V: Sessile serrated adenomas in young patients may have limited risk of malignant progression. J Clin Gastroenterol 53: e113e116, 2019. PMID: 29570172. DOI: 10.1097/MCG.0000 000000001014

7 Hyman NH, Anderson P and Blasyk H: Hyperplastic polyposis and the risk of colorectal cancer. Dis Colon Rectum 47: 21012104, 2004. PMID: 15657661. DOI: 10.1007/s10350-004-0709-6

8 Rubio CA, Stemme S, Jaramillo E and Lindblom A: Hyperplastic polyposis coli syndrome and colorectal carcinoma. Endoscopy 38 : 266-270, 2006. PMID: 16528654. DOI: 10.1055/ s-2006-925026

9 Orlowska J: Hyperplastic polyposis syndrome and the risk of colorectal cancer. Gut 61: 470-471, 2012. PMID: 21636642.

10 Bleijenberg AG, IJspeert JE, van Herwaarden YJ, Carballal S, Pellisé M, Jung G, Bisseling TM, Nagetaal ID, van Leerdam ME, van Lelyveld $\mathrm{N}$, Bessa $\mathrm{X}$, Rodríguez-Moranta $\mathrm{F}$, Bastiaansen B, de Klaver W, Rivero L, Spaander MC, Koornstra JJ, Bujanda L, Balaguer F, Dekker E. Personalised surveillance for serrated polyposis syndrome: results from a prospective 5year international cohort study. Gut, 2019. PMID: 30981990. DOI: 10.1136/gutjnl-2018-318134

11 O'Brien MJ, Yang S, Mack C, Xu H, Huang CS, Mulcahy E, Amorosino $\mathrm{M}$ and Farraye FA:Comparison of microsatellite instability, $\mathrm{CpG}$ island methylation phenotype, BRAF and KRAS status in serrated polyps and traditional adenomas indicates separate pathways to distinct colorectal carcinoma end points. Am J Surg Pathol 30: 1491-501, 2006. PMID: 17122504. DOI: 10.1097/01.pas.0000213313.36306.85

12 Bettington M, Walker N, Rosty C, Brown I, Clouston A, McKeone D, Pearson SA, Leggett $B$ and Whitehall V: Clinicopathological and molecular features of sessile serrated adenomas with dysplasia or carcinoma. Gut 66: 97-106, 2017. PMID: 26475632. DOI: 10.1136/gutjnl-2015-310456

13 Rashtak S, Rego R, Sweetser SR and Sinicrope FA: Sessile serrated polyps and colon cancer prevention. Cancer Prev Res (Phila) 10: 270-278, 2017. PMID: 28325827. DOI: 10.1158/ 1940-6207.CAPR-16-0264

14 Kashida H, Ikehara N, Hamatani S, Kudo SE and Kudo M: Endoscopic characteristics of colorectal serrated lesions. Hepatogastroenterology 58: 1163-1167, 2011. PMID: 21937375. DOI: $10.5754 /$ hge 10093 
15 Sanduleanu S, and Rutter MD: Interval colorectal cancers in inflammatory bowel disease: the grim statistics and true stories. Gastrointest Endosc Clin N Am 24: 337-348, 2014. PMID: 24975525. DOI: 10.1016/j.giec.2014.03.001

16 Snover DC, Jass JR, Fenoglio-Preiser C and Batts KP: Serrated polyps of the large intestine: a morphologic and molecular review of an evolving concept. Am J Clin Pathol 124: 380-391, 2005 PMID: 16191506. DOI: 10.1309/V2EP-TPLJ-RB3F-GHJL

17 Sheridan TB, Fenton H, Lewin MR, Burkart AL, IacobuzioDonahue CA, Frankel WL and Montgomery E: Sessile serrated adenomas with low- and high-grade dysplasia and early carcinomas: an immunohistochemical study of serrated lesions "caught in the act". Am J Clin Pathol 126: 564-571, 2006. PMID: 16938659. DOI: 10.1309/C7JE8BVL8420V5VT

18 Liu C, Walker NI, Leggett BA, Whitehall VL, Bettington ML and Rosty C: Sessile serrated adenomas with dysplasia: morphological patterns and correlations with MLH1 immunohistochemistry. Mod Pathol 30: 1728-1738, 2017. PMID: 28752838. DOI: 10.1038/ modpathol.2017.92

19 Rex DK, Ahnen DJ, Baron JA, Batts KP, Burke CA, Burt RW, Goldblum JR, Guillem JG, Kahi CJ, Kalady MF, O’Brien MJ, Odze RD, Ogino S, Parry S, Snover DC, Torlakovic EE, Wise $\mathrm{PE}$, Young $\mathrm{J}$ and Church J: Serrated lesions of the colorectum: review and recommendations from an expert panel. Am J Gastroenterol 107: 1315-1329, 2012. PMID: 22710576. DOI: 10.1038/ajg.2012.161

20 Levine DS and Haggitt RC: Normal histology of the colon. Amer J Surg Pathol 13: 966-984, 1989. PMID: 2679155.

21 Rubio CA: The histologic structure of the large bowel mucosa and the evolution of the three pathways of colonic carcinogenesis in humans and in experimental animals. In: Recent Studies on Digestive System Anatomy, e-book 3: 1-12, 2018. Available at: http://openaccessebooks.com/digestive-system-anatomy.html

22 Dahl J and Greenson JK: Colon. In: Histology for pathologists, Lippincott Williams \& Wilkins. Stacey E. Mills (eds.). Third edition, Philadelphia, PA, USA 25: 629-630, 2007.
23 Boman BM and Fields JZ: An APC: WNT counter-current-like mechanism regulates cell division along the human colonic crypt axis: a mechanism that explains how APC mutations induce proliferative abnormalities that drive colon cancer development. Front Oncol 3: 244-250, 2013. PMID: 24224156. DOI: 10.3389/ fonc.2013.00244

24 Rubio CA and Schmidt PT: Are non-dysplastic crypts with corrupted shapes the initial recordable Histological event in the development of sporadic conventional adenomas? Anticancer Res 38: 5315-5320, 2018. PMID: 30194183. DOI: 10.21873/ anticanres. 12858

25 Rubio CA, Kaufeldt A, Björk J and Jaramillo E: Maspin, a marker of serrated colorectal polyps. Anticancer Res 35: 41394144, 2015. PMID: 26124368.

26 Zheng H, Tsuneyama K, Cheng C, Takahashi H, Cui Z, Murai Y, Nomoto $\mathrm{K}$ and Takano $\mathrm{Y}$ : Maspin expression was involved in colorectal adenoma-adenocarcinoma sequence and liver metastasis of tumors. Anticancer Res 27: 259-265, 2007. PMID: 17352241.

27 Payne CM, Holubec H, Crowley-Skillicorn C, Nguyen H, Bernstein H, Wilcox G and Bernstein C: Maspin is a deoxycholateinducible, anti-apoptotic stress-response protein differentially expressed during colon carcinogenesis. Clin Exp Gastroenterol 4: 239-253, 2011. PMID: 22162927. DOI: 10.2147/CEG.S24093

28 Baker AM, Cereser B, Melton S, Fletcher AG, Rodriguez-Justo M, Tadrous PJ, Humphries A, Elia G, McDonald SA, Wright NA, Simons BD, Jansen M and Graham TA: Quantification of crypt and stem cell evolution in the normal and neoplastic human colon. Cell Rep 8: 940-947, 2014. PMID: 25127143. DOI: $10.1016 /$ j.celrep.2014.07.019
Received May 25, 2019

Revised June 19, 2019

Accepted June 20, 2019 